\title{
FEA ANALYSIS AND OPTIMIZATION OF AN ONE WAY CLUTCH USED IN AUTOMATIC TRANSMISSION BASED ON GLOBAL PARAMETERS
}

\author{
Praveen Kumar $\mathbf{K}^{1}$, Janaki Manohar $\mathbf{N}^{2}$ \\ ${ }^{\text {I}}$ Student, Mechanical Engineering (CAD/CAM), Chennai Institute of Technology, Tamil Nadu, India \\ ${ }^{2}$ Associate professor, Mechanical Engineering, Chennai Institute of Technology, Tamil Nadu, India
}

\begin{abstract}
An intent of this project is to reduce the weight of one way clutch which is being used in automotive transmission enabled sports cars. By reducing the weight we can achieve better efficiency in terms of strength and also to increase the transmission power from torque converter wherein which engaging and disengaging happens. One way roller clutch is one, when the unit rotates in one direction the rollers slip or free-wheel, but when a torque is applied in the opposite direction, the rollers lock between outer cage (cam) and inner cage, producing a wedging action and binding because of friction. The rollers are spring-loaded. Design parameters like maximum torsional deflection, minimum hoop's stress are considered for to get increased efficiency. In order to achieve this FEA analysis and optimization technique is carried here. Optimization is the mathematical discipline which is concerned with finding the maxima and minima of functions, possibly subject to constraints. Here optimization is carried out by using the global parameters optimization technique.
\end{abstract}

Keywords: FEA analysis, Global parameters, Minimum hoop`s stress, Weight $* * *$

\section{INTRODUCTION}

In this paper the main scope is about the one way roller clutch which is used in automotive transmission shaft. An one way roller clutch is used to transmits torque from engine to transmission shaft. The major purpose of this clutch is to transmit torque in one direction where it locks in another direction. This one way clutch can also be said as torque converter. In an Automatic transmission, torque converter is the starting device. Torque converter helps to multiply the torque coming from engine towards transmission. Stator, an element of torque converter helps in it.The stator of automatic transmission has a function of multiplying torque coming out of torque converter which is the input torque to the transmission.

The one way clutch on which the stator of torque converter mounted, helps to multiply torque from torque converter by locking stator rotation on one direction. While running for a mode in which torque is not multiplied, the one way clutch will help stator free wheel on its axis. Torque converter consists of an outer barrel, an inner race, a roller and spring for each roller between which attached with the outer barrel.

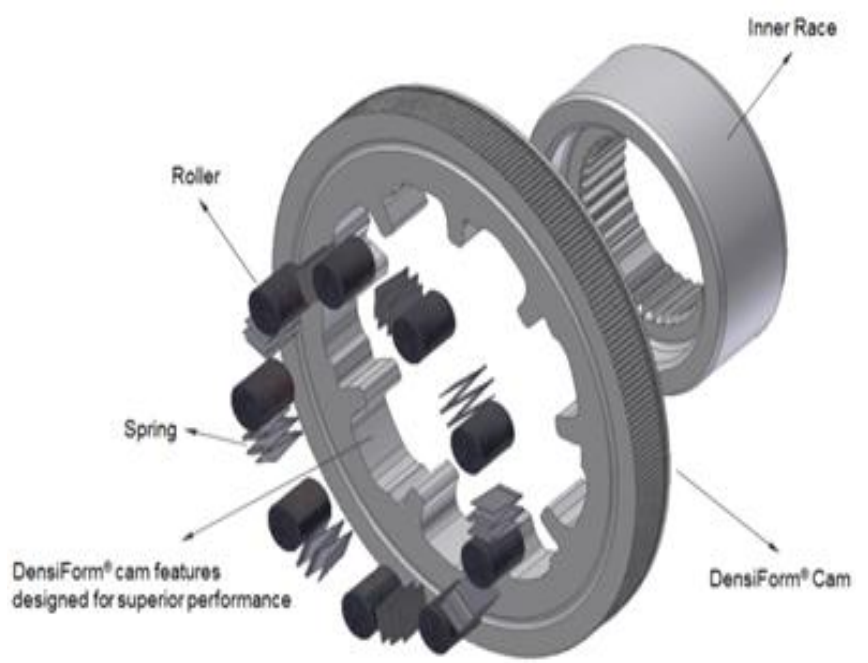

Fig -1: One way Driver Clutch

\subsection{Scope}

Here the torque converter material is taken into consideration. There are different types of material are used, depends upon the needs of the vehicle requirements. Since this paper mainly deals with sports or performance vehicle titanium alloy is taken for main consideration. Below is the list of material which are considered for this paper. 


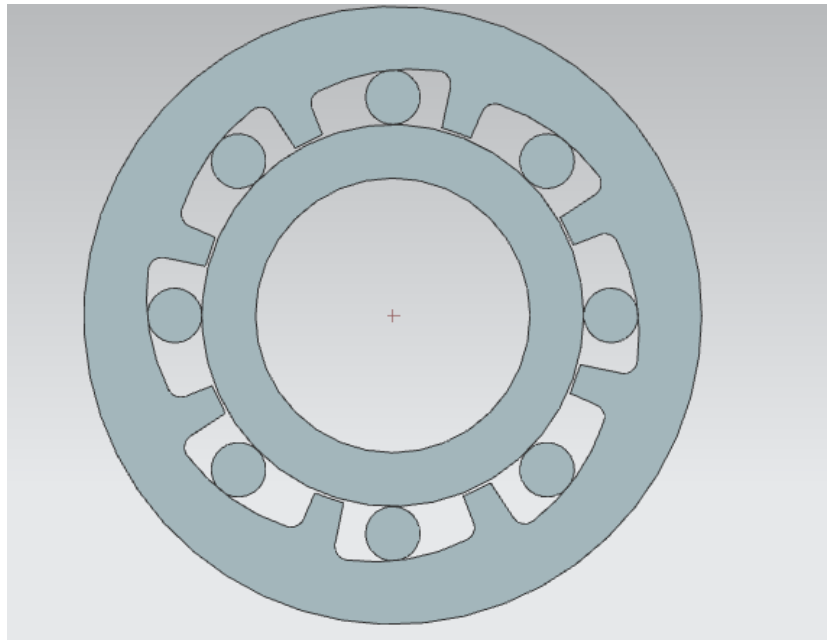

Fig -2: 3D Model of One Way Clutch

Table -1: Comparison of Different Properties

\begin{tabular}{|l|l|l|l|l|l|}
\hline $\begin{array}{l}\text { Mater } \\
\text { ial }\end{array}$ & $\begin{array}{l}\text { Youn } \\
\text { gs } \\
\text { moud } \\
\text { ulus }\end{array}$ & $\begin{array}{l}\text { Pois } \\
\text { ons } \\
\text { ratio }\end{array}$ & $\begin{array}{l}\text { Ultimate } \\
\text { strength( } \\
\text { Mpa) }\end{array}$ & $\begin{array}{l}\text { Yield } \\
\text { strength( } \\
\text { Mpa) }\end{array}$ & $\begin{array}{l}\text { Density(kg } \\
\left./ \mathrm{mm}^{3}\right)\end{array}$ \\
\hline $\begin{array}{l}\text { Ti- } \\
\text { 6Al- } \\
\text { 4V }\end{array}$ & $\begin{array}{l}1.21 \mathrm{E} \\
+05\end{array}$ & 0.34 & 845 & 805 & $4.43 \mathrm{E}-06$ \\
\hline $\begin{array}{l}\text { AISI } \\
\text { Steel } \\
\text { Mara } \\
\text { ging }\end{array}$ & $\begin{array}{l}1.80 \mathrm{E} \\
+05\end{array}$ & 0.31 & 1515 & 1482 & $8.00 \mathrm{E}-06$ \\
\hline $\begin{array}{l}\text { AISI } \\
\text { Steel } \\
4340\end{array}$ & $\begin{array}{l}1.93 \mathrm{E} \\
+05\end{array}$ & 0.28 & 1240 & 1178 & $7.85 \mathrm{E}-06$ \\
\hline
\end{tabular}

\subsection{Optimization}

After analysing optimization is carried out by means of using the global parameters. An optimization is one which gives the maximum and minimum with respect with an analysis. Here the major parameters are maximum torsional deflection, minimum hoop`s stress. For this genetic algorithm is used. A genetic algorithm (or GA) is a search technique used in computing to find true or approximate solutions to optimization and search problems. Genetic algorithms are categorized as global search heuristics. Genetic algorithms are a particular class of evolutionary algorithms that use techniques inspired by evolutionary biology such as inheritance, mutation, selection, and crossover (also called recombination).

\section{DESIGN PROCEDURE}

All these parameters for this one way roller clutch depends upon the strut angle. Strut angle is one which is an angle between the projected lines from the roller contact position. So depends upon the strut angle the roller works, so if the roller is in good contact with the barrel and the race means it provides greater slippage.

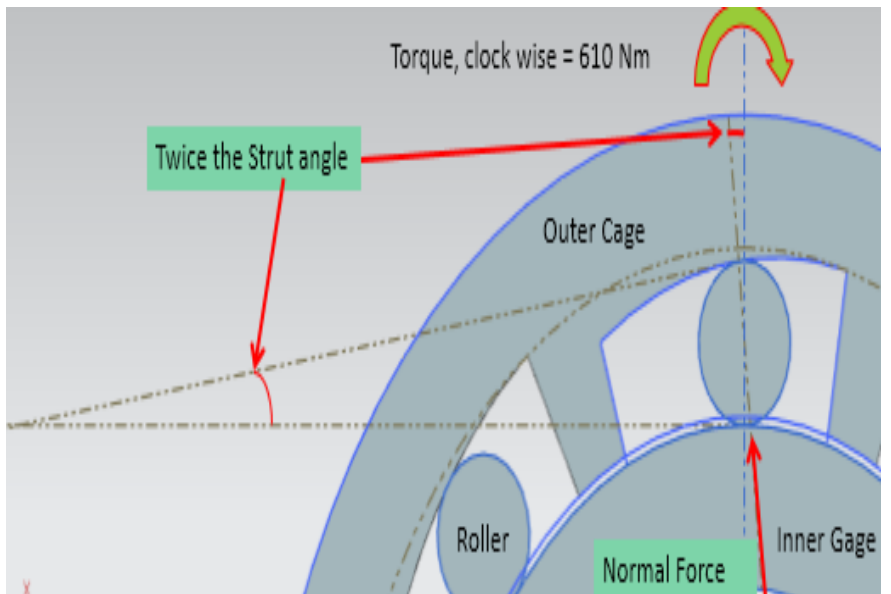

Fig -3: Free Diagram, One Way Clutch

The equation which are used in this paper according to shell theory

The maximum torque which can be applied on one way clutch is given by

$$
T=8300 n l\left(\frac{r R^{2}}{r+R}\right) \sin \alpha
$$

The hoop stress developed in One way clutch, considering shell theory

$$
\sigma_{h}=49800\left[\frac{r n R}{\pi(r+R) a}\right]\left[\frac{b^{2}+a^{2}}{b^{2}-a^{2}}\right] \cos \alpha
$$

Where $\alpha$ is strut angle, $\mathrm{R}$ is Inner cage Outer radius, $\mathrm{r}$ is Roller radius, " $\mathrm{a}$ " is Outer cage inner radius and " $\mathrm{b}$ " is Outer cage inner radius, " $n$ " is number of rollers, and "l" is width of one way clutch.

\subsection{Meshing and Analysis}

Here the meshing is carried out by using commercially available software.

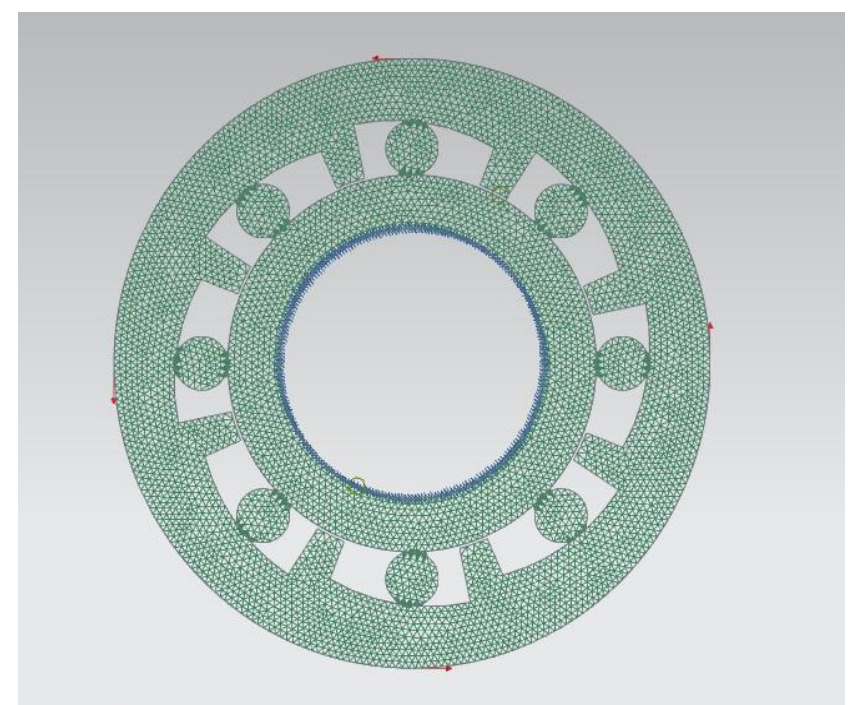

Fig -4: The Model as Mesh with Boundary Conditions 
After meshing analysis is carried out for different materials. In the analysis von-misses stress, maximum principle stress, and torsional deflection are taken for the comparison. After this optimization is carried out.

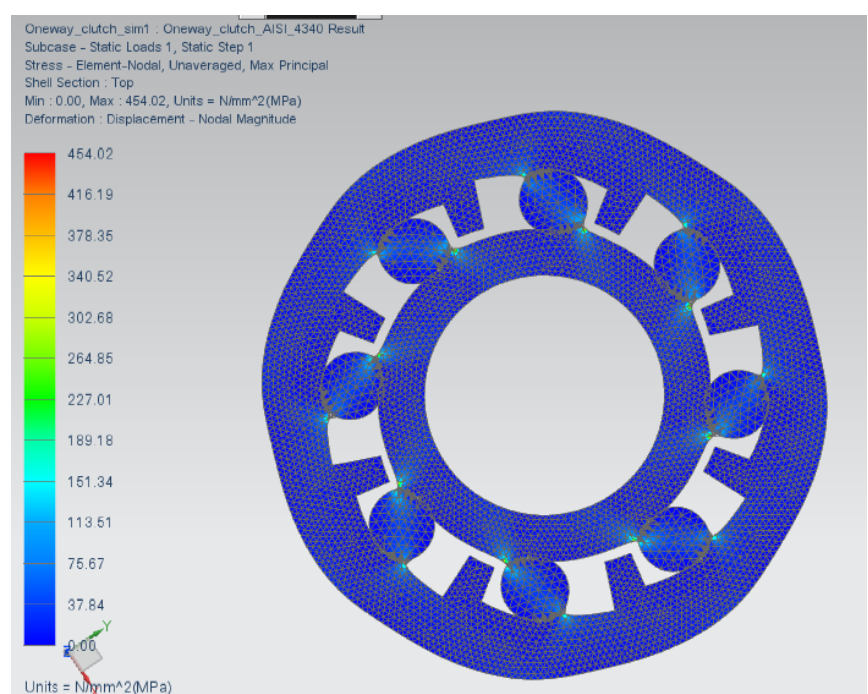

Fig -5: For Material AISI Steel 4340, the Max, Principal Stress $=454.02 \mathrm{Mpa}$.

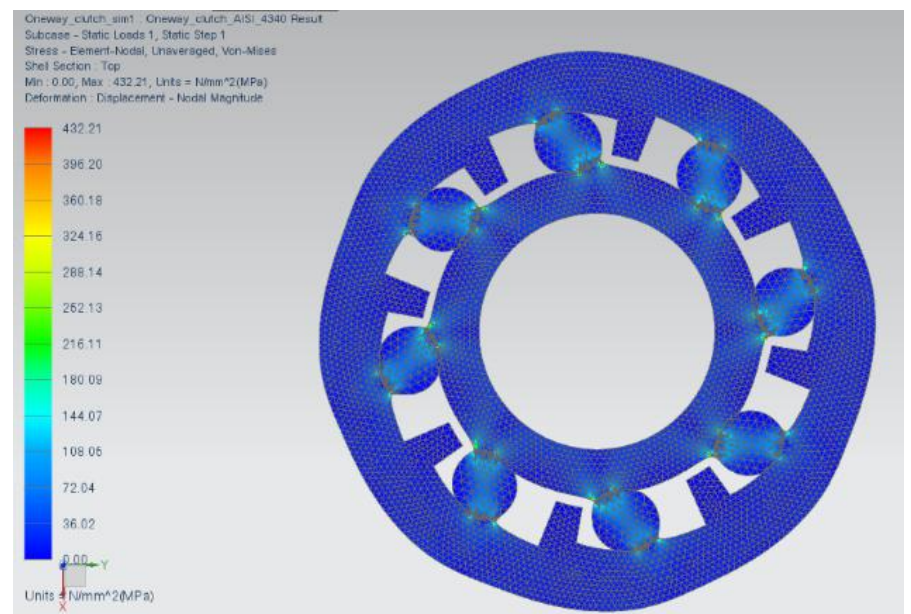

Fig -6: The Von Mises Stress = 432.21 Mpa.

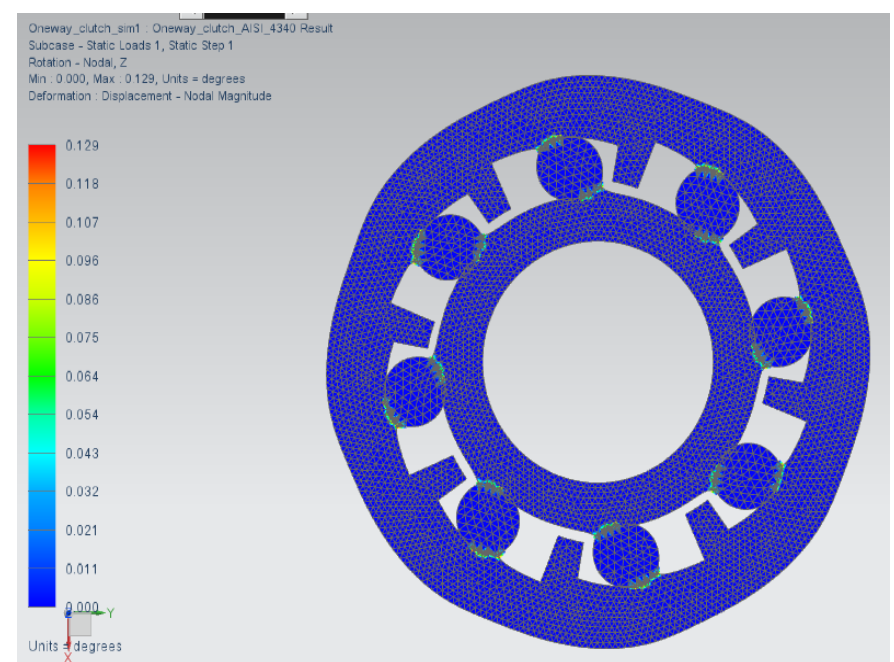

Fig -7: Torsional Deflection is 0.129 Degrees.

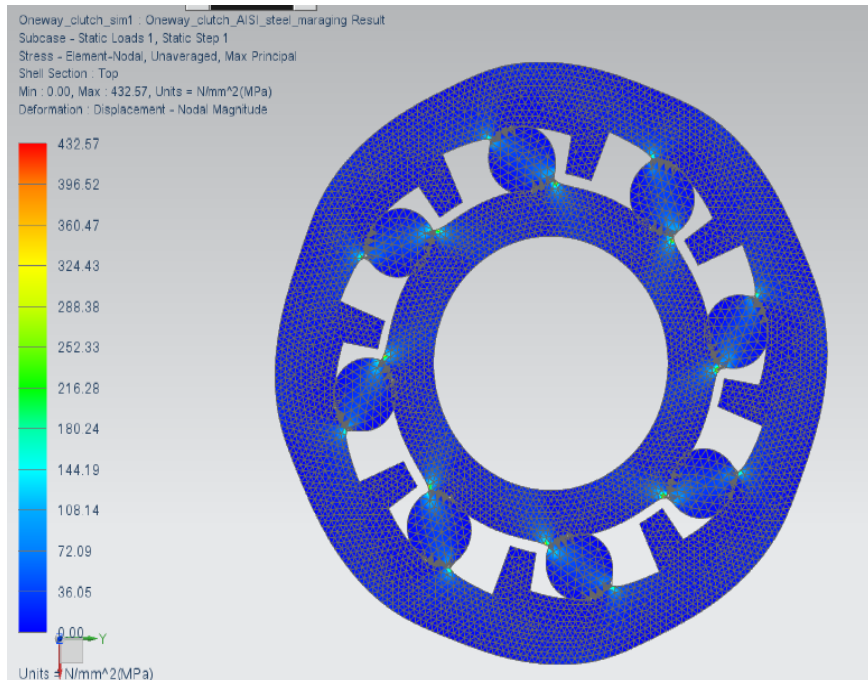

Fig -8: For Material AISI Steel Maraging, The Max, Principal Stress = 432.57 Mpa.

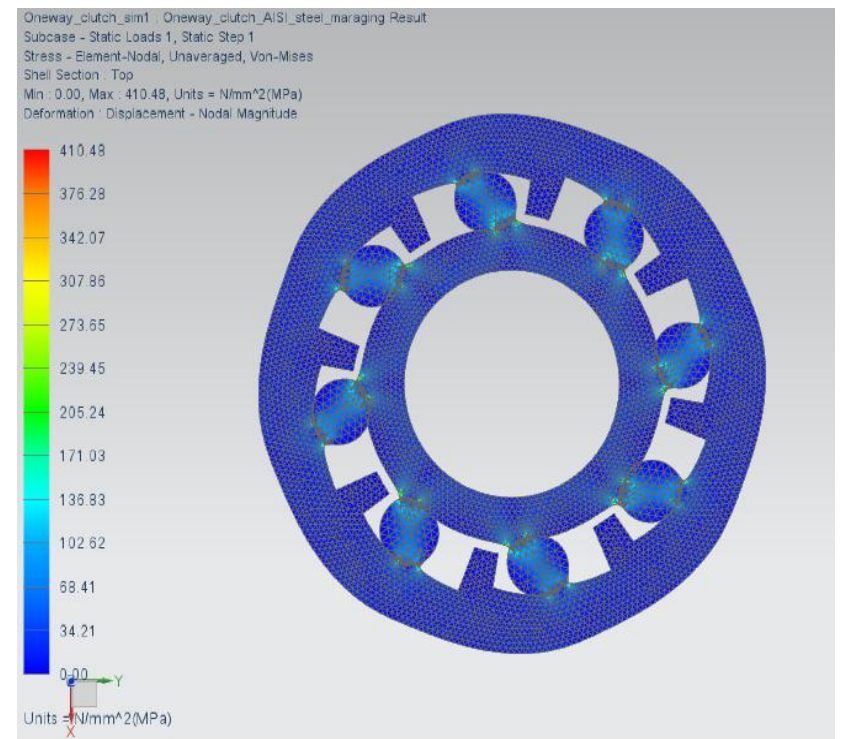

Fig -9: The Von Mises Stress $=410.48 \mathrm{Mpa}$

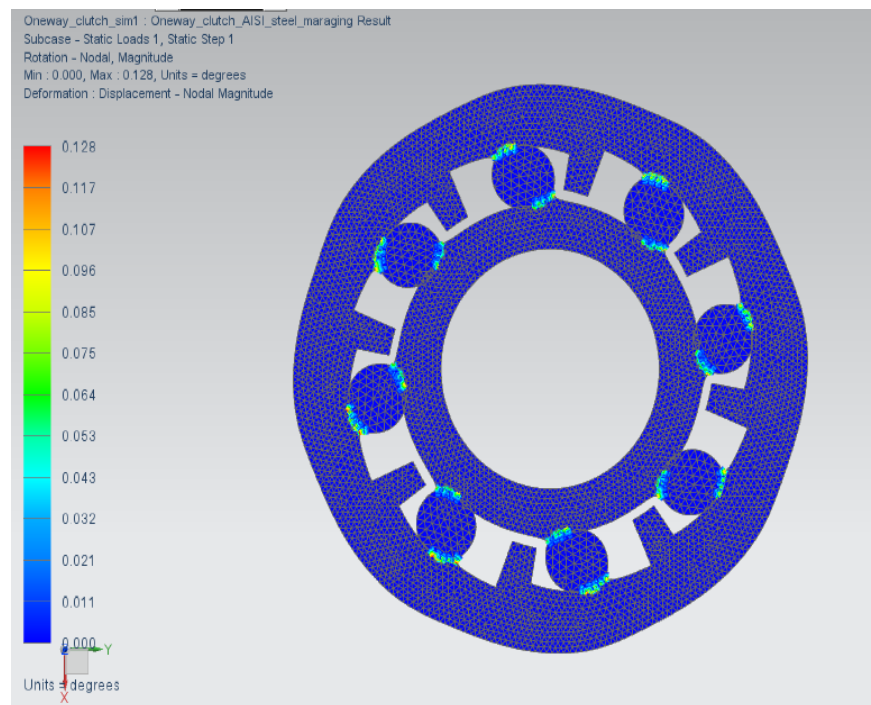

Fig -10: Torsional Deflection is 0.128 Degrees 


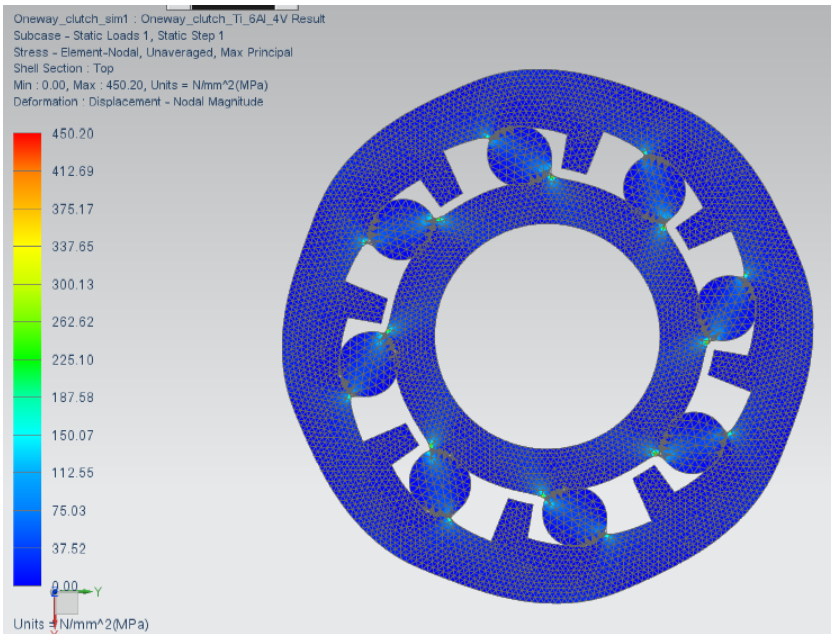

Fig -11: For Material Ti6Al4v, The Max, Principal Stress = 454.20Mpa.

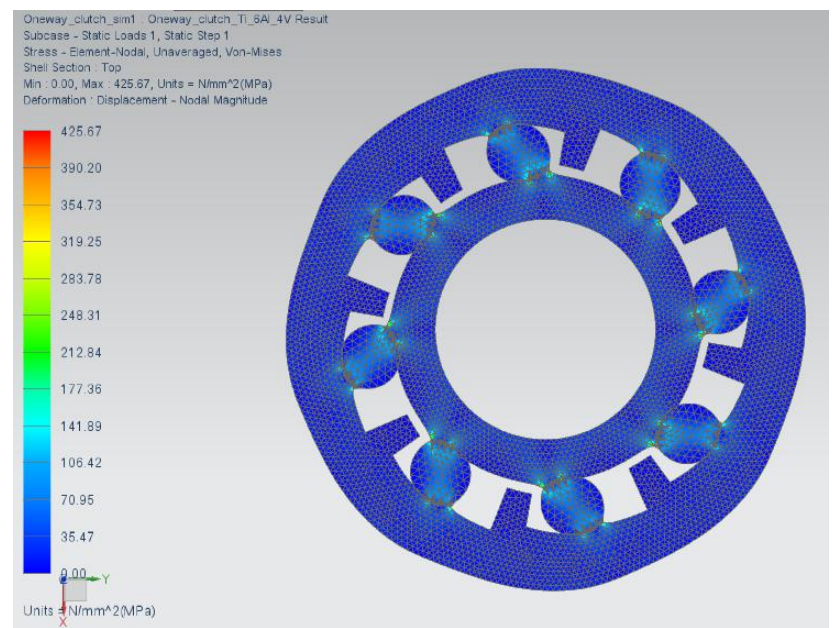

Fig -12: The Von Mises Stress = 425.67 Mpa

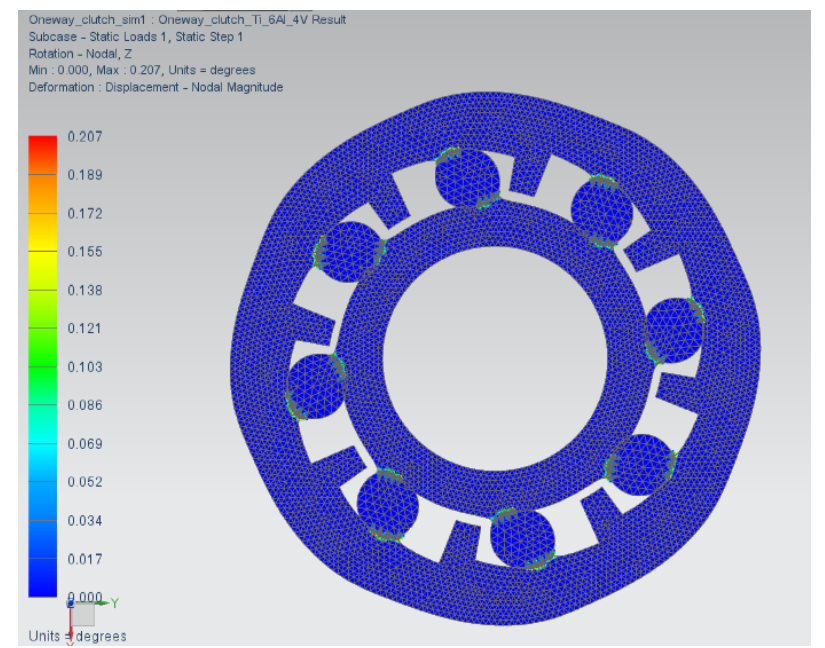

Fig -13: Torsional Deflection is 0.207 Degrees

- For Ti-6Al-4V, the factor of safety $=805 / 450.20=$ 1.79.

- $\quad$ For AISI Steel Maraging, the factor of safety = $1482 / 432.57=3.43$.

- For AISI Steel 4340, the factor of safety = $1178 / 454.02=2.59$.
- But the Ti6Al4V is in a superior advantage in Low weight compared to other two steel alloys, $4.43<7.85$ $<8$.

- Torsional deflection is comparable when related to maximum deflection limit for the application is 0.25 degrees. (greater than $0.207>0.129>0.128$ )

\subsection{Optimization}

The basic idea of a genetic algorithm is to generate a new set of designs (population) from the current set such that the average fitness of the population is improved. The process is continued until a stopping criterion is satisfied or the number of iterations exceeds a specified limit. Three genetic operators are used to accomplish this task: reproduction, crossover, and mutation. Siemens NX lets you select from local and global algorithm types.

Local algorithms are generally better for finding a precise solution when you know generally where the desired answer should be found. The answer returned by a local optimization is highly dependent on the starting point of the analysis, and may miss a better answer located in a different part of the design space.

Design objective:

Minimize Weight

Design Constraints:

The maximum torsional deflection should not exceed 0.25 degrees.

Maximum principal stress should not be more than $500 \mathrm{Mpa}$ Design variables:

- $\quad 23<$ Length of One way clutch $<22 \mathrm{~mm}$.

- $\quad 94.5<$ Outer cage outer diameter< $84.5 \mathrm{~mm}$.

- $\quad 8<$ Twice the strut angle $<6 \quad$ 4) $762.5<$ Maximum torque can be applied< $610 \mathrm{Nm}$ Optimization: Altair Hyper opt solver.

Table -2: Optimization Results

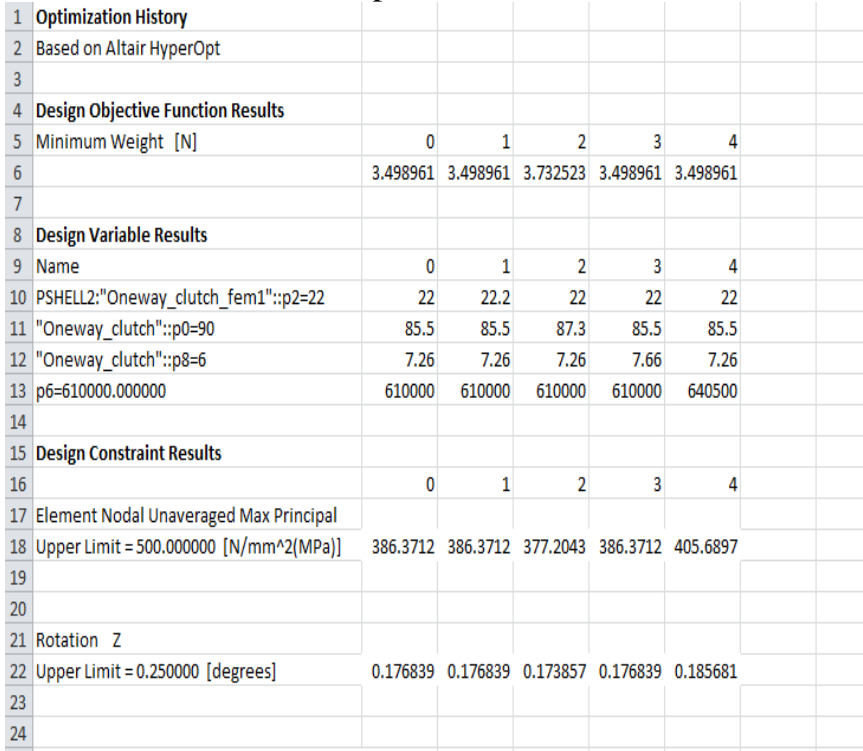




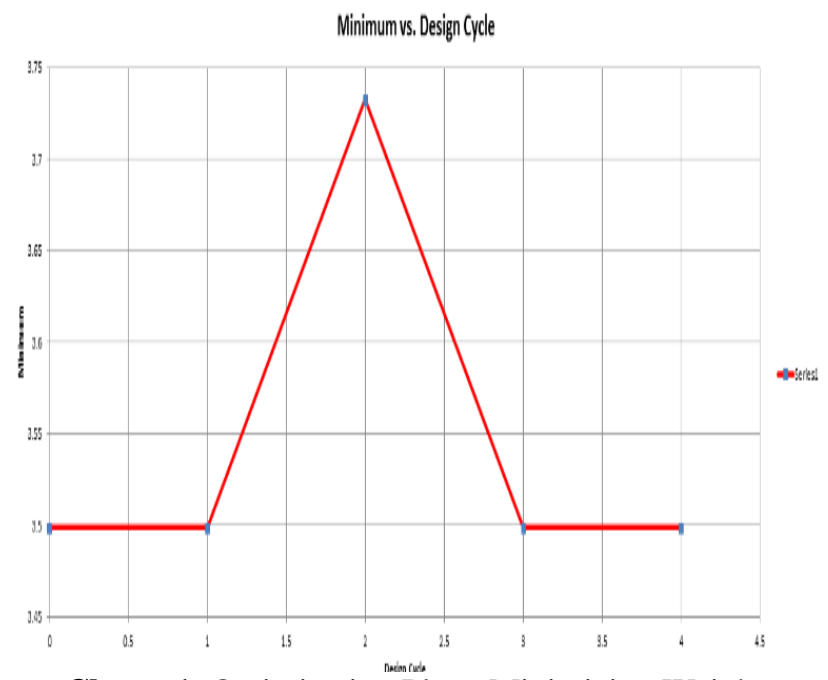

Chart -1: Optimization Plots: Minimizing Weight

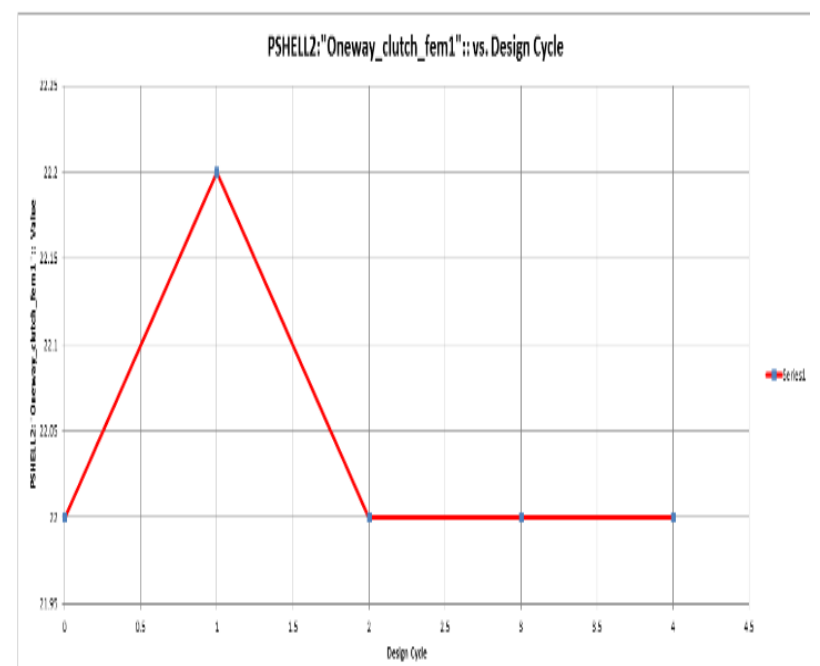

Chart -2: Optimization Plots: Length of Clutch Vs Design Cycles

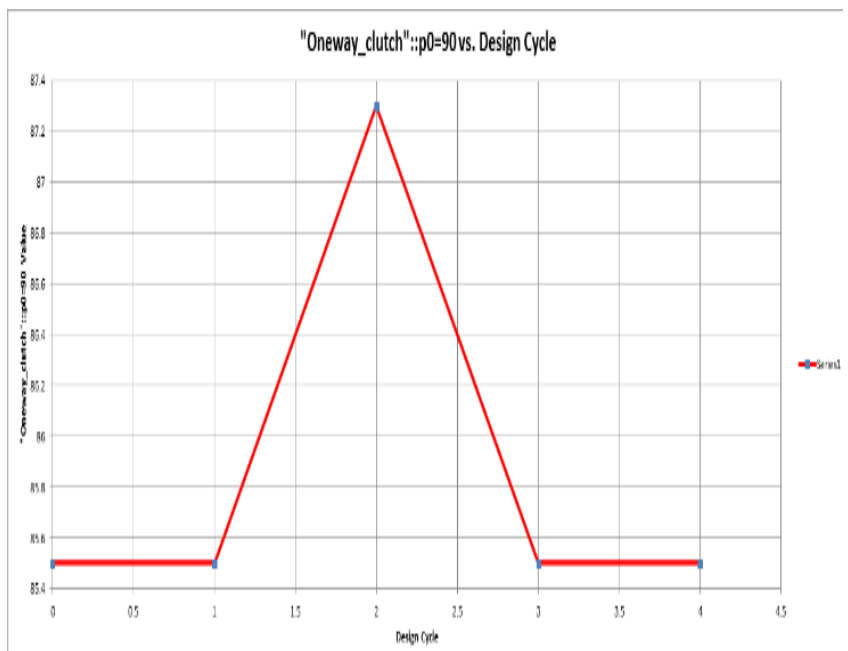

Chart -3: Optimization Plots: Outer Diameter of Clutch Vs Design Cycles.

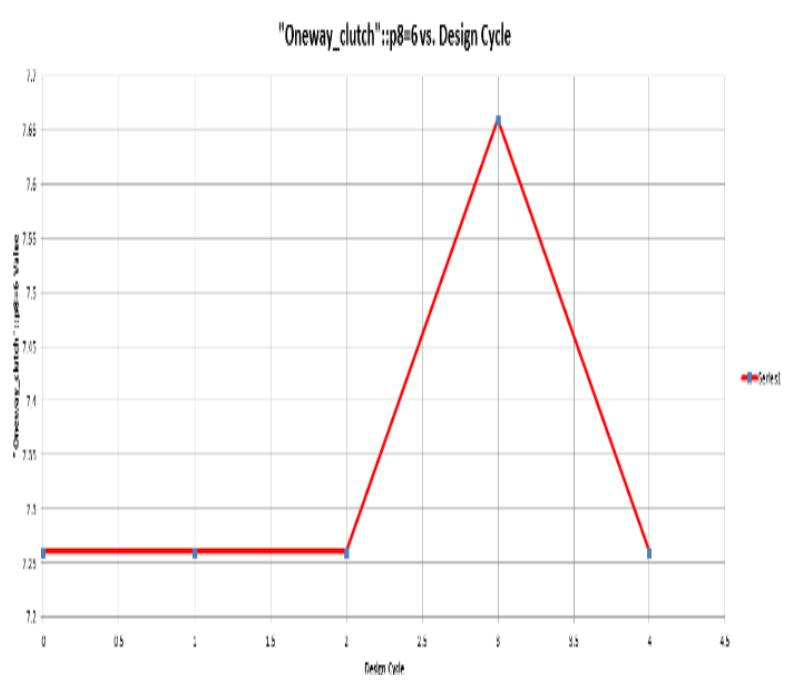

Chart -4: Optimization Plots: Twice the Strut Angle Vs Design Cycles

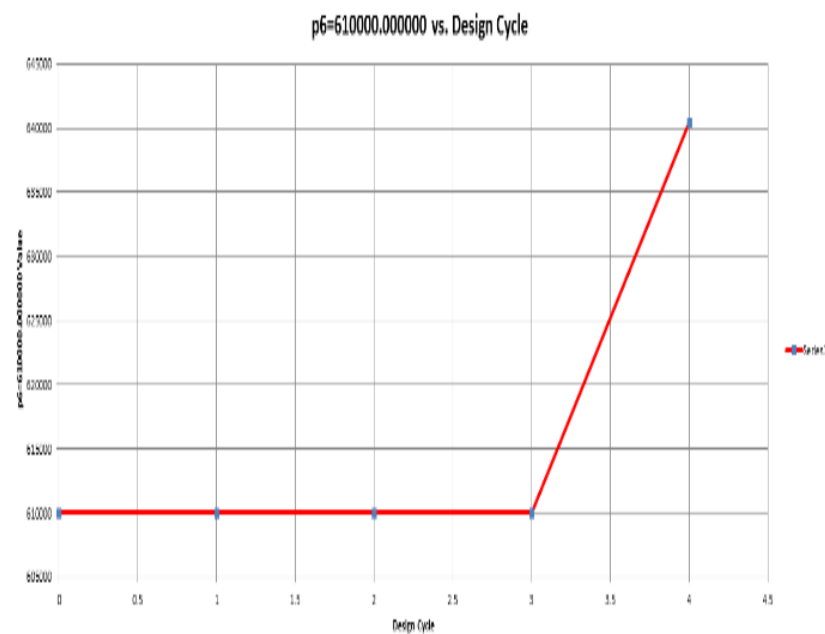

Chart -5: Optimization Plots: Maximum Torque Can Be Applied Vs Design Cycles

\section{CONCLUSION}

One way clutch is superior Torque application device used in automatic transmission. Comparison study of competitive materials for devices is undergone in this project to check the torsional capability of the device. Though the results for stresses and deflection of one way clutch based on Ti6Al4V (Titanium Alloy) is very close to what other materials produce, Ti6Al4V have a great advantage in weight. The weight of same part made out of Ti6Al4V weigh almost half as AISI steel $4340 \quad(7.85 / 4.43=1.772-$ Ratios of densities) Based on the FEA results and comparison of densities, Ti6Al4V have a superior advantage over other two metals if performance $\&$ packaging of device is considered

\section{REFERENCES}

[1]. Wei Xue and Rob Pyle "optimal design of roller one way clutch for starter drives" SAE technical paper 2004.

[2]. http://www.rsgear.com/blog/2011/5/23/understandingandanalyzing-manual-transmission- failures.aspx. 
[3]. Vikas Waghole, Rajiv Tiwari "optimization of needle bearing design using novel hybrid methods" department of mechanical engineering, Indian Institute of Technology Guwahati, 781039 Assam, India.

[4]. Hu Ding, Jean W.Zu "Effect of one-way clutch on the nonlinear vibration of belt-drive system with acontinous belt model" Shanghai institute of applied mathematics and mechanics, china

\section{BIOGRAPHY}

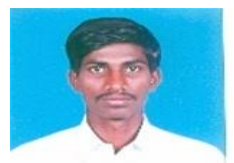

Am Praveen Kumar doing my masters in computer aided design and manufacturing in Chennai Institute of Technology. Since I have a more passion in design and analysis and also because of my own interest am publishing this paper. 